DOI: $10.13037 /$ ci.vol21n45.6240

\title{
Jornalismo esportivo e relações de gênero: o espaço para a participação feminina
}

SPORTS JOURNALISM AND GENDER RELATIONS: THE SPACE FOR FEMALE PARTICIPATION

\author{
L Noemi Correa Bueno ${ }^{1}$ \\ ORCID: https://orcid.org/0000-0002-2579-587X \\ (Centro Universitário Adventista de São Paulo, Campus Educação a Distância São Paulo - SP, \\ Brasil)
}

\section{José Carlos Marques ${ }^{2}$}

ORCID: https://orcid.org/0000-0001-6175-4162

(Universidade Estadual Paulista, Programa de Pós-Graduação em Comunicação, São Paulo - SP, Brasil)

\section{Resumo}

Este artigo procura analisar a participação de profissionais mulheres numa área historicamente conhecida como androcêntrica: o jornalismo sobre esporte praticado na TV no Brasil. Para verificar o panorama da participação de homens e mulheres em conteúdos sobre esporte, foram realizados, nos anos de 2017 e 2018, dois tipos de pesquisa: um que mensurou a participação de profissionais femininos e masculinos em programas esportivos da TV aberta brasileira; e outro que entrevistou mulheres participantes desses programas. $\mathrm{O}$ resultado indicou uma baixa participação feminina $(11,4 \%)$, restando às mulheres quase sempre o cargo de apresentadoras ou repórteres, cabendo aos homens as funções de narradores e comentaristas, atestando a persistência neste campo de um ethos sob domínio masculino.

Palavras-chave: Jornalismo. Gênero. Esporte. TV brasileira.
Recebido em 20/08/2019. Aprovado em 28/09/2019.

\section{Abstract}

This article seeks to analyze the participation of female professionals in an area historically known as androcentric: journalism about the sport practiced on TV in Brazil. To verify the overview of the participation of men and women in sports content, in 2017 and 2018, two types of research were conducted: one that measured the participation of female and male professionals in sports programs on Brazilian TV; and another one who interviewed women participates in these programs. The result indicates a low female participation (11.4\%), reestablishing women almost always the presentations or reporters, while men have narrative and commentary functions, attesting the persistence in this field of ethics under male domain.

Keywords: Journalism. Gender. Sport. Brazilian TV. 


\section{Introdução}

Durante os últimos anos, temos observado no Brasil, e em grande parte do mundo ocidental, mudanças significativas nas relações de gênero, resultando em novas possibilidades de atuação nos campos familiares, políticos, sociais e econômicos tanto para homens como para mulheres. Essas transformações são decorrentes de outras maneiras de compreender e visualizar os sujeitos e suas respectivas funções sociais promovidas por anos de luta de movimentos e grupos de mulheres que reivindicavam (e ainda reivindicam) igualar direitos masculinos e femininos, bem como suprimir o preconceito e as diferenças de gênero. A partir disso, é possível verificarmos a conquista ao voto feminino, a ampliação do acesso ao ensino superior e ao mercado de trabalho por parte das mulheres, novas estruturas familiares, e maior independência econômica feminina, por exemplo (BUENO, 2015, p. 01).

Porém, apesar desse avanço, as diferenças e preconceitos de gênero ainda estão presentes na sociedade brasileira. Por isso, na contemporaneidade, os movimentos feministas ainda são atuantes, não mais reivindicando o direito ao voto eà profissionalização, além do acesso ao mercado de trabalho (reivindicações primárias desse movimento), mas buscando conquistar efetivamente o espaço público com novas representações, bem como novas maneiras de compreender o que é ser mulher (ALVAREZ, 2002; PISCITELLI, 2018).

Considerando os novos posicionamentos e pautas reivindicatórias, este artigo propõe-se a refletir sobre o jornalismo esportivo, o qual envolve duas instituições historicamente reconhecidas por manter espaços majoritariamente masculinos, reforçando preconceitos de gênero: o esporte e o jornalismo. Para tal, foram analisadas e mensuradas as participações femininas nas funções de narração, apresentação e comentário em programas esportivos da televisão aberta brasileira (transmitidos na região metropolitana de Campinas), veiculados em novembro de 2017. O período de análise escolhido justiçase pelo fato de, naquela ocasião, estarem ocorrendo importantes eventos esportivos no Brasil, como a final do campeonato brasileiro de futebol, o Grande Prêmio de Fórmula 1 do Brasil e jogos de ida e volta da final da Libertadores. ${ }^{1}$

\footnotetext{
1 Cabe referir ainda que este estudo não se debruçou sobre a programação da TV por assinatura no Brasil, cuja produção poderá ser merecedora de uma investigação semelhante em outra oportunidade, haja vista o aparecimento de algumas profissionais mulheres ocupando esporadicamente postos antes ocupados apenas por homens. Na TV aberta brasileira, por outro lado, a presença de mulheres tem ganhado um novo dinamismo em 2019, mostrando um panorama distinto daquele pesquisado às vésperas da Copa do Mundo de 2018, período em que se realiza nossa pesquisa.
} 
Além disso, também foram realizadas entrevistas com essas profissionais, com o objetivo de verificar como elas compreendem os espaços e possibilidades de atuações femininas nesse campo.

Considerando a hipótese de que nos programas esportivos veiculados na televisão aberta brasileira ainda existe uma cultura androcêntrica, resultando em possibilidades de atuações e participações diferentes para mulheres e homens, este artigo propõe: 1) quantificar a presença masculina e feminina nas funções de narração, apresentação e comentários; 2) avaliar se ocorre predominância de alguns dos gêneros em alguma função específica das elencadas neste trabalho; 3) verificar o que as profissionais envolvidas compreendem desse ambiente; e 4) traçar relações entre os dados coletados com estereótipos de gênero.

Este estudo é importante para a sociedade brasileira, pois o esporte é uma instância que mantém e eterniza (e, portanto, também poderia questionar) representações a respeito de masculinidades e feminilidades (DEVIDE, 2005; KNIJNIK, 2010; DACOSTA, TURINI, 2002; CONCEIÇÃO, CORTEZ, SIMÕES, 2004; GOELLNER, 2004; DUNNING, ELIAS, 1985; BIRREL, COLE, 1990; APPLEBY, FOSTER, 2013; THEBERGE, 2000). Da mesma forma, os meios de comunicação também possuem papel importante na elaboração, manutenção e/ou questionamento de representações sociais, pois projeta imagens a respeito de valores, fatos, crenças e realidades, que interferem na construção de representações por parte de seus receptores, mesmo esses sendo responsáveis pelas interpretações dessas projeções (BECKER, 2005; CHARAUDEAU, 2016; PRADO, 2005).

Assim, a discussão a respeito de representações femininas pelos meios de comunicação, bem como da participação de mulheres no ambiente esportivo, é importante para a conquista das novas pautas feministas referentes às construções de novas identidades e representações de mulheres. Por meio desta análise é possível verificar o protagonismo feminino nessas esferas e se esse espaço ocupado é coerente com definições estereotipadas de gênero ou se questiona essas definições, propondo outras possibilidades de atuação que ultrapassem barreiras androcêntricas.

\section{Referencial teórico}

Como apontamos, é inegável o avanço das conquistas feministas no Brasil. No entanto, apesar dos avanços, ainda há diversas pautas de reivindicação não alcançadas. 
Após o direito ao voto, o direito à inserção no mercado de trabalho e o direito à educação serem efetivados, o movimento feminista passou a se dedicar a novas esferas, como a da representação e a construção de masculinidades e feminilidades.

Nesse sentido, feministas reformularam sua pauta de discussão, criticando a maneira como gênero é entendido e construído a partir de valores binários e heteronormativos. Passaram, então, a reivindicar e debater a respeito de representações e identidades, indicando o que significa o gênero e como esse é produzido, aceito e/ou questionado pela sociedade.

Em relação a essa construção de identidade genderizada, estudos feministas apontam que o gênero é resultante de uma repetida estilização de um determinado corpo em um sistema regulador rígido, promovendo uma falsa aparência de naturalidade. Por isso, ao estudar gênero, é necessário considerar as diferentes formas e configurações de poder em seus respectivos contextos culturais, sociais e históricos. Afinal, o gênero pode ser construído de diferentes maneiras conforme as relações de poder que o cercam, pois sua formação perpassa processos ideológicos, políticos e econômicos. Em detrimento disso, feministas consideram que sujeitos são plurais, contingentes e heterogêneos; e, criticam o binarismo, o essencialismo e o universalismo responsáveis pela compreensão errônea de que a mulher consiste em uma categoria unitária (BUTLER, 2003; SCOTT, 2005; PISCITELLI, 2018; MARIANO, 2005; BRAH, 2006; FRASER, 2010).

Considerando que uma das formas de naturalização e construção de gêneros ocorre por meio de representações mediáticas, alguns grupos e coletivos de mulheres passaram a atuar junto aos meios de comunicação, utilizando-os para promover discussões emancipatórias, como ocorre com os grupos Empodere Duas Mulheres (https://www. empodereduasmulheres.com/), Força Meninas (http://frmeninas.com.br/), Coletivo de Jornalistas Feministas Nísia Floresta (https://coletivonisiafloresta.wordpress.com/), Revista AzMina (https://azmina.com.br/), entre outros. Além disso, outra forma de atuação dos movimentos contemporâneos em relação aos meios é a de analisar e propor novas representações mediáticas ou mesmo até a de reivindicar a presença de mais mulheres nas esferas de produção dessas representações.

Conforme aponta Guacira Lopes Louro (2008), essa discussão tem ocorrido desde os anos de 1960, a partir da exposição de grupos denominados como minorias a respeito de seus descontentamentos em relação à forma como eram representados. Tais grupos exigiam ainda outras representações sobre suas histórias, dilemas, modos de vida e estéticas, a partir de uma reivindicação que abarcasse também o direito de se autorrepresentar. 
Nesse sentido, a participação da mulher enquanto criadora de conteúdos mediáticos também é bastante relevante. Assim, a presença delas como diretoras, produtoras e escritoras em diferentes formatos e segmentos mediáticos (seja no entretenimento ou no jornalismo) é importante para a elaboração de representações femininas em diferentes segmentos da sociedade, bem como de representações mais adequadas e coerentes com a realidade das mulheres.

Em relação, especificamente, à profissão de jornalismo (objeto deste artigo), observamos que o ingresso da mulher nessa categoria foi tardio. No Brasil, é apenas a partir de 1920 que são encontrados os primeiros dados de mulheres trabalhando como jornalistas (praticamente 100 anos depois do início da imprensa brasileira), sendo que nesses poucos casos as mulheres atuavam majoritariamente em suplementos femininos. A inserção foi de tal forma lenta que ainda na década de 1950, o número de jornalistas no Estado de São Paulo não alcançava a 40 (RAMOS, 2010).

Às mulheres eram, geralmente, oferecidos cargos em suplementos femininos, colunas do gênero, ou assuntos 'leves'. Como se a gente não pudesse pensar macro. Todas as jornalistas que hoje praticam a profissão nas muitas redações, em cargos expoentes e tantas delas brilhantes, devem, com certeza, a essas pioneiras o espaço que hoje tem na imprensa. Mulheres que começaram, sim, nos suplementos femininos, porque queriam fincar o pé na redação, e com isso, abriram caminho para as demais (LOPEZ, 2010, apud RAMOS, 2010, p. 258).

Em relação a isso, Hamilton Ribeiro descreve como eram os ambientes da imprensa brasileira em seus primórdios e até o início da inserção de mulheres nessa categoria profissional.

As empresas jornalísticas eram pensadas e construídas como ambiente de sauna brega: só para homem. Nem havia banheiro feminino. No Estadão, à noite, quando fervia o trabalho jornalístico, as mulheres não eram aceitas nem na mesa telefônica. Havia mulheres como telefonistas, mas só durante o dia. À noite, um homem é que operava. Mulher podia ser telefonista, faxineira ou servia para fazer o café: circulava na área de serviço (RIBEIRO 1998, 31).

E se a inserção da mulher no jornalismo foi lenta, podemos afirmar que no jornalismo esportivo foi ainda mais lenta e gradual. De acordo com Regina Ramos (2010, 
p. 238), Maria Helena Rangel (cujo registro profissional data 1948) é considerada a primeira jornalista mulher do segmento esportivo brasileiro. E conforme o Museu do Futebol (2016), as primeiras mulheres a se destacarem nessa área na televisão brasileira foram Claudete Troiano e Luciana Mariano, que atuaram como narradoras nos anos de 1980.

Outras duas jornalistas consideradas pioneiras no campo dos esportes no Brasil foram Mylena Ciribelli (que iniciou em 1988 atuando nos boletins Olímpicos de Seul para a TV Manchete) e Isabela Scalabrini, que também na década de 1980, passou atuar no Globo Esporte da TV Globo, cobrindo matérias de diversas modalidades - exceto futebol que ainda era considerado de exclusividade masculina (MUSEU DO FUTEBOL, 2016; TAVARES, 2015; RAMOS, 2010). Em relação ao início de sua carreira, a jornalista, Isabela Scalabrini aponta que:

não pegava matéria do Jornal Nacional e nem pegava futebol. Eu notava que tinha essa resistência mesmo sabe! Uma mulher em campo? O que ela vai poder fazer? Isso demorou bastante, eu entrei em 80 , mas só consegui começar a fazer matéria boa, de rede, em 83 (SCALABRINI apud SIQUEIRA, 2015, p. 42).

Vale ainda lembrar que o universo esportivo foi construído a partir de perspectivas masculinas. Conforme a socióloga e pesquisadora Salomé Marivoet (2015, p. 01), “os princípios do desporto moderno, o ethos competitivo e exaltação das proezas físicas em confrontações sujeitas a um código de honra de 'cavalheiros'-, que constituíram os valores da cultura masculina dominante no século XIX - reservaram-no por excelência aos homens", sendo que, no Brasil, a participação feminina nesta atividade ao longo do Século XX foi permitida apenas aos poucos, e de maneira não igualitária (DEVIDE, 2005).

Portanto, podemos afirmar que ao adentrar no jornalismo esportivo, as jornalistas pioneiras não apenas conquistaram novos espaços e o direito de escolher por uma carreira profissional de seus interesses, mas também quebraram (ou pelo menos fragilizaram) o conceito simbólico da associação dessas duas esferas (jornalismo e esporte) como de interesse e competência exclusivamente masculinos. Assim, a mudança não aconteceu apenas em relação à troca de um ambiente doméstico por um ambiente profissional (direito que às mulheres ainda reivindicavam no período de inserção das pioneiras no jornalismo esportivo), mas também pelo acesso a dois ambientes que eram considerados tipicamente masculinos, sendo que o esporte ainda é classificado por muitos como um campo masculino. 


\section{Metodologia}

Para alcançar os objetivos deste artigo, foram utilizadas a análise de conteúdo e a entrevista como formas de coletas de dados e informações. A primeira, a análise do conteúdo, foi responsável pela mensuração da presença de homens e mulheres atuando como apresentadoras(es), comentaristas, narradoras(es) ou comentaristas convidadas(os) em todos os programas de esportes veiculados na televisão aberta brasileira (transmitidos na região metropolitana de Campinas). Essas informações permitiram uma comparação entre a presença e as funções dessas(es) profissionais conforme seus respectivos gêneros.

Após essa etapa, foram realizadas entrevistas abertas com seis jornalistas mulheres que atuavam em programas de esportes da televisão aberta brasileira no período utilizado para a análise de conteúdo. As entrevistas foram realizadas entre 24 de novembro de 2017 a 06 de abril de 2018, sendo uma parte realizada via Skype e a outra presencialmente na cidade de São Paulo.

A proposta dessas entrevistas consistia em "recolher respostas a partir da experiência subjetiva das fontes selecionadas por deter informações que desejávamos conhecer" (DUARTE, 2015, p. 63). Neste caso, buscou-se compreender a visão e perspectivas das jornalistas a respeito dos seus contextos profissionais, principalmente em relação ao quadro encontrado na primeira parte desta pesquisa: o de uma baixa participação feminina nesses programas e uma participação não relacionada à produção de conteúdos, mas praticamente exclusiva com função de apresentação. Assim, a partir dessas entrevistas, foi possível alcançar um dos objetivos desta pesquisa, o de verificar se a baixa participação feminina neste campo jornalístico é decorrente das escolhas femininas ou de uma prática de mercado naturalizada ao longo dos anos.

\section{As profissionais de comunicação em programas de esportes televisivos}

No período analisado (novembro de 2017), foram contabilizados 20 diferentes programas esportivos ${ }^{2}$ veiculados em 205 edições na televisão aberta brasileira. Para tal, foram considerados todos os programas televisivos cuja temática central envolvia

2 RIT Esportes (RIT), Brasil Esportes (TV Aparecida), Porshe Cup (Bandeirantes), Band Esporte Clube (Bandeirantes), Jogo Aberto (Bandeirantes), Os Donos da Bola (Bandeirantes), Terceiro Tempo (Bandeirantes), NBB Caixa (Bandeirantes), Bola na Rede (Rede TV), Super Liga do Vôlei (Rede TV), Super Faixa do Esporte (Rede TV), Brasileirão Série B (Rede TV), Gazeta Esportiva (TV Gazeta), Mesa Redonda (TV Gazeta), Esporte fantástico (TV Record), Cartão Verde (TV Cultura), Esporte Espetacular (Rede Globo), Futebol (Rede Globo), Fórmula 1 (Rede Globo). 
elementos do esporte, incluindo, inclusive, transmissões gravadas ou ao vivo, da prática de alguma modalidade esportiva.

Para essa análise foram verificadas todas as 205 edições (que foram gravadas ou disponibilizadas na íntegra pelas emissoras em seus respectivos sites), identificando os nomes das(os) profissionais nas funções de narração, comentarista e apresentação, de forma a considerar apenas 1 profissional caso a(o) mesma(o) tenha participado em diferentes edições de um mesmo programa. A(o) mesma(o) profissional somente foi contabilizada(o) mais de uma vez, caso tenha participado de mais de 1 programa diferente ${ }^{3}$. Em relação a isso, vale apontar que a rotatividade de profissionais se concentrou na função comentarista convidada(o), cuja não repetição de profissionais já era esperada, devido à própria característica da função (participação especial).

Dos 20 programas de esportes, apenas em 9 deles houve a presença de uma ou mais mulheres nas funções estudadas para este artigo, ou seja, em 55\% dos programas a figura masculina foi exclusiva. No caso, o objetivo consistia em mensurar as funções de apresentação, narração e comentário, mas constatou-se que as mulheres assumiram apenas o cargo de apresentação, exceto por um caso de comentarista convidada e outra que além de ser apresentadora também é mediadora de debates. Sendo assim, nenhuma mulher esteve presente como comentarista fixa ou narradora.

Os dados coletados nessa fase da pesquisa foram agrupados de maneira a formar a Tabela 1, disponível a seguir.

Tabela 1 - Comentaristas, narradoras(es) e apresentadoras(es) em programas de esporte televisivo brasileiros, conforme o gênero

\begin{tabular}{|c|c|c|c|c|c|}
\hline & & $\hat{\sigma}$ & & q & Total \\
\hline Apresentação & 13 & $54,2 \%$ & 11 & $45,8 \%$ & 24 \\
\hline Apresentação e Mediação & 3 & $75,0 \%$ & 1 & $25,0 \%$ & 4 \\
\hline Comentário & 45 & $100,0 \%$ & 0 & $0,0 \%$ & 45 \\
\hline Comentário (convidada(o)) & 41 & $97,6 \%$ & 1 & $2,4 \%$ & 42 \\
\hline Narração & 6 & $100,0 \%$ & 0 & $0,0 \%$ & 6 \\
\hline Acompanhamento de Redes Sociais & 1 & $50,0 \%$ & 1 & $50,0 \%$ & 2 \\
\hline Total & 109 & $88,6 \%$ & 14 & $11,4 \%$ & 123 \\
\hline
\end{tabular}

Fonte: Elaboração dos autores.

\footnotetext{
3 No caso, temos, por exemplo, 14 profissionais do gênero feminino contabilizadas nos programas esportivos, que representam de fato apenas 11 mulheres diferentes, pois três delas (Larissa Erthal, Michele Gianella e Paula Vilhena) participaram de dois diferentes programas.
} 
Observamos, portanto, que as mulheres representam apenas $11,4 \%$ dos profissionais elencados nesta pesquisa, enquanto os homens representam 88,6\%. Das funções em que há maior equidade de participação entre os gêneros, destaca-se a de acompanhamento de redes sociais, sendo que há 1 profissional do gênero feminino e outro do gênero masculino, e a de apresentação onde foram constatadas 11 mulheres (45,8\%) e 13 homens (54,2\%). Também podemos apontar em relação à função de apresentação e mediação, na qual 1 mulher (25\%) e 3 homens (75\%) assumem esse cargo. Por fim, apontamos ainda em relação à ocupação como comentarista convidada(o), em que foi constatada a presença de 1 mulher (2,4\%) e 41 homens $(97,6 \%)$ e como comentarista e narrador onde havia 45 e 6 homens, respectivamente, e nenhuma mulher.

Dessa forma, verificamos que as mulheres atuam quase exclusivamente como apresentadoras, tendo a função de apontar os dados que serão noticiados e debatidos, ou seja, apenas transmitem as informações e interagem com as(os) telespectadoras(es). Assim, além da baixa participação feminina (11,4\%), essas ainda não contemplam todas as possibilidades de atuação no jornalismo esportivo, pois seu envolvimento se restringe ao cargo de apresentação, sem efetiva participação na produção e no processo estratégico do conteúdo esportivo.

Percebe-se, portanto, que nesses programas compete à mulher indicar o que será veiculado na edição vigente, apontando os conteúdos que serão debatidos e aprofundados pelos homens, responsáveis pela narração e comentário, sendo eles reconhecidos como detentores do conhecimento esportivo aos quais cabe o poder da palavra e o discurso competente. A função de comentário repercute nesse status já que por definição um comentarista é justamente aquele que irá contextualizar e analisar a notícia, enriquecendo com outros dados e informações (LEMOS apud PORTAL IMPRENSA, 2017, p. 01), por isso, para exercer essa função é necessário conhecimento vasto sobre o esporte, as equipes, fatos históricos relevantes e técnicas (TAVARES, 2011). Da mesma forma para a narração é importante que exista conhecimento das técnicas e regras do esporte, bem como das equipes e seus integrantes. Por isso, para assumir essas funções é necessário reconhecimento por parte do programa e dos seus telespectadores da competência esportiva da(o) profissional contratada(o), afinal, será responsável efetivamente pelo debate e produção do conteúdo.

Outro fator destacado na pesquisa é que das 14 mulheres presentes nesses programas, nove compartilharam a função de apresentação com um colega do gênero masculino, ou seja, não assumiram sozinhas a responsabilidade de transmissão das informações, pois 
estiveram acompanhadas de um homem nesse processo. É evidente que a situação da apresentação em dupla implica em divisões de tarefas e funções, e, nesse caso, notou-se que $75 \%$ das mulheres contam com a colaboração de algum homem nesse processo, que assume parte das responsabilidades.

Como já elencado, a inserção da mulher no jornalismo esportivo no Brasil foi lenta e gradual. Conforme Núbia Tavares (2015), ainda em meados da década de 1990, o futebol ainda era considerado esporte para homens, e, por isso, poucas mulheres se arriscavam no jornalismo esportivo, mesmo em funções de apresentação. Na contemporaneidade o cenário tem apresentado mudanças, mas ainda há barreiras pelas quais essas jornalistas precisam enfrentar ao adentrar nesse campo. Considerando esse aspecto, além da mensuração do número de profissionais, este artigo também propôs realizar entrevistas com jornalistas que atuam no jornalismo esportivo televisivo no Brasil, com intuito de verificar como essas mulheres compreendem essa diferença de atuação entre profissionais homens e mulheres. $\mathrm{O}$ objetivo inicial consistia em entrevistar as $11^{4}$ jornalistas identificadas na análise descrita anteriormente, porém, houve retorno e possibilidade de agendamento com apenas 6 delas, que foram entrevistadas via Skype ou presencialmente na cidade de São Paulo.

É interessante ainda elencarmos que a inserção das mulheres nesse cenário televisivo pode ser considerada tão recente, que muitas das entrevistadas para a pesquisa deste artigo, de certa forma, se consideram precursoras nesse campo ou desbravadoras de um ambiente em que havia poucas mulheres, como pode ser observado nos depoimentos: "Eu tinha uma impressão de que era muito masculino, antes de entrar" (ENTREVISTADA B, 2018), "eu peguei uma fase que não tinha muita mulher, então você sente mesmo uma resistência" (ENTREVISTADA E, 2018), "Eu fui uma das primeiras (...), quando eu comecei na Manchete, eu era a única apresentadora" (ENTREVISTADA D, 2018), "Quando eu comecei não tinham ainda muitos nomes femininos famosos, como o da Renata Fan, tínhamos algumas mulheres, mas ainda poucas na apresentação de programas de esporte" (ENTREVISTADA A, 2017), "até então só tinha homens nesse programa e não tinha nenhuma mulher" (ENTREVISTADA C, 2017).

Vemos, portanto, que em 2017 e 2018 (anos de realização da entrevista), 70 anos após o registro de uma das primeiras mulheres trabalhando no segmento do jornalismo esportivo (RAMOS, 2010, p. 238), as entrevistadas demonstram consciência de que foram desbravadoras e pioneiras neste ambiente masculinizado.

4 Lembrando que a contabilização de 14 profissionais do gênero feminino envolve a contagem de mulheres que participaram de mais de um programa. No caso, essas 14 constituem de fato apenas 11 mulheres diferentes, pois três delas (Larissa Erthal, Michele Gianella e Paula Vilhena) participaram de dois diferentes programas. 
As entrevistadas também se posicionaram em relação especificamente ao objeto deste artigo (atuação como apresentadora, narradora e comentarista). Sobre isso, a Entrevistada A (2017) apontou que essa não participação das mulheres como comentaristas e narradoras é decorrente de uma cultura preconceituosa, que apesar de permitir a entrada das mulheres como apresentadoras e repórteres, ainda as exclui dos espaços de comentário e narração.

$\mathrm{Eu}$ acho que existe uma barreira, eu acho que existe um preconceito. Eu acho que as mulheres estão apresentando, estão reportando fatos, mas ainda não tem espaço para que elas comentem, emitam sua opinião, para que elas tenham voz. No programa eu dou minha opinião, mas não é minha função. Minha função é ser apresentadora (ENTREVISTADAA, 2017).

Essa afirmação vai ao encontro da posição da Entrevistada D (2018), que afirma que ainda há falta de oportunidades para as mulheres que gostariam de ocupar essas funções e que acredita que, também, há falta de interesse do público em ouvir uma narração na voz feminina. Nesse sentido, ela aponta ter conhecido algumas jornalistas que tentaram ingressar como narradoras e comentaristas, mas não tiveram sucesso. Aliás, ela mesma demonstra interesse na função de narração, porém não encontra uma oportunidade para atuar como tal.

Quanto à narradora e comentarista que ainda têm poucas, eu acho que é por causa da falta de espaço. Eu acho que muita mulher gostaria de narrar. Eu, por exemplo, uma das ideias também era de eu fazer narração. Mas ainda é um espaço bem masculino, e acho que tá difícil de abrir isso. E tudo bem, acho que as pessoas podem ter o gosto de achar que a narração tem mais a ver com a voz masculina, mas ao mesmo tempo, poderia se testar e ver como é que as pessoas reagiriam. Acho que da mesma maneira que os homens gostam de mulheres na hora de narrar os gols (os resumos dos gols para os programas), também podem gostar de uma mulher narrando o jogo (...). Mas eu cheguei a pensar nisso seriamente. Já vi algumas mulheres tentando, mas só. Talvez porque a maioria prefira mesmo os homens narrando, porque eles já estão fazendo isso há muitos anos e tá todo mundo já acostumado .... mas tudo é uma questão de hábito, de se habituar (ENTREVISTADA D, 2018).

Em um outro depoimento, a Entrevistada B (2018) aponta que nunca recebeu um convite para ser comentarista ou narradora, mas que não possui interesse, pois acredita 
que ainda não está preparada para isso. Segundo ela, essa é uma tarefa para "caras que sabem", o que nos permite inferir que, em sua fala, a entrevistada também acaba por naturalizar a ideia de que o universo da locução do futebol compete aos homens (ou "caras" como ela apontou). Ao final, ela ainda reforça que o conhecimento é possível ser adquirido estudando e, portanto, todas(os) podem conquistar, mas coloca ainda que a emotividade da fala para narração não é uma tarefa fácil, e que ela gostaria de ver uma mulher fazer isso. Nesse sentido, percebemos como o estereótipo de gênero em relação ao espaço esportivo também está presente nas próprias mulheres que atuam nesse campo, a despeito de elas eventualmente acreditarem e desejarem possibilidades de mudança nesse cenário.

Nunca me falaram aqui se eu queria narrar ou comentar, para mim ninguém nunca falou nada disso, e eu mesmo nunca nem imaginei eu fazendo isso, eu na minha humildade sempre achei que isso era tarefa do nosso amigo Maurício Torres, caras que sabem, que sacam muito de futebol e acho que para narrar você tem que saber e se for comentar saber mais ainda, você tem que ter um histórico, mas é óbvio que para você narrar você também tem que saber. Vai também para aquele negócio de que você pode estudar e conseguir narrar, mas colocar emoção, eu não sei, eu quero até ver (uma mulher fazer), juro! (ENTREVISTADA B, 2018).

Seguindo essa ideia de competência, a Entrevistada C (2017), elenca que a mulher precisa de muito conhecimento preparação e experiência para se tornar comentarista ou narradora, pois sua eficiência será testada. Ainda segundo ela, assumir essas funções é incompatível com pessoas com menos de 40 anos, justamente pela necessidade de aquisição de credibilidade, resultado de anos de trabalho no âmbito esportivo. Ela reforça ainda que apesar de ela acreditar que essa trajetória seja a mesma para homens e mulheres (ter reconhecimento para assumir esses cargos), para as mulheres há mais trabalho para conquistar essa credibilidade: "Se você for novo, vai saber (fazer comentário ou narração)? Não vai! aí sua credibilidade cai, ainda mais sendo mulher. Se você é mulher e quer ficar nesse âmbito esportivo, você tem que ser muito boa”. Segundo ela, para uma mulher ingressar nesse campo, ela deverá quebrar paradigmas e enfrentar muitas barreiras.

Eu acho que a mulher como narradora vai ser um pouco mais difícil. Eu acredito que isso possa um dia dar certo, só que essa mulher vai ter que ser muito boa. 
Ela vai ter que quebrar paradigmas. Eu acredito que isso vai acontecer, mas acho que vai ser mais difícil de ser sustentado (...), a pessoa vai ter que ser muito boa (...). Acho que esse é o segredo, o espaço tem, mas você tem de ser boa. Não pode ser qualquer uma. E em relação a ser comentarista, muita gente fala, ah por que você não quer ser comentarista? Vamos lá, hoje eu tenho 30 anos de idade. Os bons comentaristas de mesa redonda, o Juca Kfouri, Gian Oddi, Arnaldo ... todos têm mais de 40 anos de idade. Tem que ser experiente para isso. Você tem que ter experiência e bagagem. Não é porque você tem 20 anos de idade que tem credibilidade para ser comentarista (...). Se você for novo, vai saber (fazer comentários)? Não vai! Aí sua credibilidade cai, ainda mais sendo mulher. Se você é mulher e quer ficar nesse âmbito esportivo, você tem que ser muito boa (ENTREVISTADA C, 2018).

Das entrevistadas, apenas uma elencou que a ausência de mulheres como narradoras e comentaristas seria decorrente da falta de interesse delas em assumir essas funções, pois não conhece ninguém que teria esse desejo. Ela apontou que a narração é tradicionalmente um espaço masculino, e por isso, as mulheres não possuem vontade de realizar essa atividade. E se, no caso das mulheres "não pode ser qualquer uma", talvez no caso dos homens essa questão seletiva não se coloque nos mesmos moldes.

Ainda em relação à fala dela de que não conhece nenhuma mulher que queira ser narradora, vale ressaltarmos que é colega de trabalho da Entrevistada D, que afirmou ter interesse em trabalhar com isso. Nesse sentido, é interessante verificarmos como a possibilidade de sonhar e galgar novos espaços também se encontra, de certa forma, silenciada, já que ambas não compartilham sobre isso.

Eu acho que tem muito menos interesse das mulheres em relação à narração [...]. Mas a questão da narração eu acho que é, por mim falando, que é falta de interesse, eu não teria vontade narrar. A narração ao vivo, eu acho que ainda não tem a ver com uma figura feminina, é uma coisa que vem de muita tradição de rádio, de transmissão de esportes muito mais masculino e então eu não teria vontade e com as pessoas que eu converso ninguém nunca me falou algo do tipo: "nossa, eu tenho uma vontade de ser narradora" (ENTREVISTADA E, 2018).

Nas entrevistas ainda foi citado um caso inovador de possibilidade de participação feminina como narradora. O caso citado foi da emissora FOX, que se encontrava em fase de teste para lançamento de narradoras no período da Copa do Mundo FIFA (2018). Em 
relação a isso, a Entrevistada B (2018) elencou uma possível não aceitação do público, indagando: “quem será que vai querer ouvir o que elas falam?". Segundo ela, as(os) telespectadoras(es) costumam ser exigentes e intransigentes com os comentaristas e narradores atuais e acredita que isso se maximizaria com a presença de profissionais do gênero feminino.

Essa semana eu vi um negócio que eu achei muito curioso, são duas meninas na Fox, narrando jogo, mas é um teste. Mas fiquei pensando, será que vão assistir? Será que vão querer ouvir? Quem é o público? Por que a televisão é um veículo de massa, então, quem vai ligar para ver? Você tem que fazer o que as pessoas querem ver, é legal porque é diferente, mas fiquei pensando, “cara quem será que alguém vai querer ouvir o que elas falam, né?" Eu fiquei tentando responder essa pergunta. Talvez senhoras, ou pessoas que estão de saco cheio, porque eu acho que quem gosta muito de futebol, entende e é homem, tem um preconceito: “o que essa mulher tá comentando aí?” Por outro lado, meu marido mesmo que entende muito de esporte e gosta, ele reclama dos caras também que falam coisa errada (...). Vai que quebra e as pessoas acham legal, diferente... Mas eu não sei, eu acho que tem um caminho longo aí (...). Quando eles forem ao ar eu quero ver. Cara, deve ser no mínimo diferente. E eu espero que seja diferente, porque se for igual, qual é a graça? Eu acho que a malandragem seria fazer algo um pouco diferente (...). Eu estou curiosa para ver isso aí (ENTREVISTADA B, 2018).

Por fim, ela afirmou que tem interesse em conhecer a atuação dessas narradoras, e que possui expectativas de que o trabalho delas seja diferente do apresentado convencionalmente pelos homens e que coloquem um "toque feminino" durante a transmissão dos jogos.

\section{Considerações finais}

Apesar das mudanças na sociedade brasileira em relação às questões de gênero, ainda há segmentos e setores marcadamente sexistas, com divisões de atribuições e espaços diferentes para homens e mulheres. Neste artigo, observou-se que o jornalismo esportivo é uma dessas instâncias que ainda reflete e, consequentemente, contribui com a manutenção da desigualdade de gênero. 
De acordo com a pesquisa apresentada, as mulheres representam apenas $11,4 \%$ das(os) profissionais estudadas(os) nesta pesquisa, sendo que essas exercem apenas a função de apresentação. Em relação à profissão de comentarista (cuja função é analisar os jogos e apresentar uma visão sobre os acontecimentos, a partir de observações e análises dos fatos) e em relação à narração (cuja responsabilidade é relatar o jogo), não houve alguma participação feminina, portanto, é possível afirmar que o ethos do discurso jornalístico no âmbito esportivo compete exclusivamente aos homens (no caso, do jornalismo da televisão aberta).

Assim, observa-se que à mulher cabe exibir os conteúdos que serão aprofundados, debatidos e produzidos por homens (narradores, comentaristas e convidados) cabendo a esses o poder da palavra, o discurso competente e, consequentemente, o debate efetivo sobre o esporte e suas vertentes.

De uma forma geral, a ausência da participação feminina como narradoras e comentaristas foi justificada pelas entrevistadas pela falta de oportunidades dada às mulheres, preconceitos de gênero, ausência de mulheres com experiência sólida na área dos esportes, não interesse da audiência que mulheres ocupem essa função, e, ainda houve uma entrevistada que apontou a falta de interesse das próprias mulheres em assumirem os cargos de narração e comentário.

De acordo com entrevistas realizadas com jornalistas que atuam nesse ambiente, a não participação da mulher nessas funções pode ser justificada por alguns fatores como: preconceitos de gênero, falta de oportunidades dada às mulheres; ausência de mulheres com experiência esportiva; não interesse da audiência que mulheres ocupem essa função, e, ainda houve uma entrevistada que apontou a falta de interesse das próprias mulheres em assumirem os cargos de narração e comentário.

Como apontamos ao longo deste artigo, a invisibilidade feminina no campo do jornalismo esportivo é decorrente de uma trajetória histórica na qual mulheres se encontravam privadas de participação e envolvimento com a profissionalização esportiva e jornalística, exclusão também presente em diversos segmentos da sociedade, que propiciava possibilidades de escolhas diferentes para homens e mulheres (ALVAREZ, 2002; MORENO, 2008).

Sendo a sociedade brasileira ainda marcada por valores sexistas e androcêntricos, podemos apontar que a baixa participação feminina no jornalismo esportivo indicada nesta pesquisa não é uma coincidência ou decorrente de melhor capacidade masculina em relação ao jornalismo e ao esporte, mas resultado de estereótipos de gênero naturalizados historicamente por meio de uma trajetória de exclusão feminina. 
Por isso, a discussão dessas relações (como a promovida por este trabalho) é importante para reflexão a respeito de novas possibilidades de atuações masculinas e femininas, de maneira a promover uma desnaturalização de espaços e oportunidades criados a partir de compreensões sexistas, binárias e heteronormativas. Ao longo de 2019, uma mudança significativa neste cenário vem sendo colocada em prática na TV aberta brasileira, especialmente pela Rede Globo, com a presença de mulheres atuando no comentário de jogos de futebol, fenômeno impulsionado pelas transmissões de jogos da Copa do Mundo Feminina de Futebol no mês de junho. Trata-se de um fenômeno recente, que merece novas investigações a partir de agora, confrontando-se as análises com alguns dos resultados que este artigo procurou modestamente apresentar ao longo destas páginas.

\section{Referências}

ALVAREZ, Ana de Miguel. O feminismo ontem e hoje. Lisboa: Ela por ela, 2002.

APPLEBY, K.; FOSTER, Elaine. Gender and sport participation. In: ROPER, Emily A. (Ed.). Gender relations in sport. Rotterdam: Sense Publishers, 2013.

BECKER, H. S. Métodos de pesquisa em Ciências Sociais. São Paulo: Pioneira, 1999.

BIRREL, S.; COLE, C. L. Doublé fault: Renne Richards and the construction and naturalization of difference. Sociology of sport journal, v. 7, n. 01, p. 1-21, 1990.

BRAH, Avtar. Diferença, diversidade, diferenciação. Cadernos Pagu, n. 26, p.329-376, janeirojunho de 2006.

BUENO, Noemi Correa; MARQUES, José Carlos. Quem é quem nos programas esportivos de televisão: uma análise das questões de gênero no Cartãozinho Verde, da TV Cultura. Disponível em: http://portalintercom.org.br/anais/nacional2015/resumos/R10-0795-1.pdf. Acesso em: 20 dez 2015.

BUTLER, Judith. Problemas de gênero. Rio de Janeiro: Civilização Brasileira, 2008.

CHARAUDEAU, Patrick. A televisão é capaz de informar? Matrizes, São Paulo, v.10, n. 2, p. 13-23, maio/ago. 2016. 
CONCEIÇÃO, Paulo Felix Marcelino; CORTEZ, José Alberto Aguilar; SIMÕES, Antonio Carlos. Mulher e esporte de competição e rendimento: as várias fases do social, do biológico e do psicológico. In: KNIJNIK, Jorge D.; SIMÕES, Antonio C (Orgs.). O mundo psicossocial da mulher no esporte: comportamento, gênero e desempenho. São Paulo: Aleph, 2004. P. 133 a 152.

DACOSTA, L.; TURINI, M. (2002). Coletânea de textos em estudos olímpicos. Rio de Janeiro: Gama Filho, 2002.

DEVIDE, Fabiano P. Gênero e mulheres no esporte. Ijuí: Unijuí, 2005.

DUARTE, Jorge. Entrevista em profundidade. In: BARROS, A.; DUARTE, Jorge (Org.). Métodos e técnicas de pesquisa em comunicação. São Paulo: Atlas, 2015.

DUNNING, Eric; ELIAS, Norbert. A busca da excitação. Lisboa: Difel, 1985.

FRASER, Nancy. Repensando o reconhecimento. Enfoques. Vol 9, n. 1, ago 2010, p. 114-128.

GOELLNER, Silvana. V. Mulher e esporte no Brasil: fragmento de uma história generificada. In: Knijnik, J. D. \& Simões, A. C (orgs). O mundo psicossocial da mulher no esporte. São Paulo: Aleph, 2004. p. 359-373.

KNIJINIK, Jorge D (Org.). Gênero e esporte. Rio de Janeiro: Apicuri, 2010.

LOURO, Guacira Lopes. Gênero e sexualidade. Pro-Posições, v. 19, n. 2, - p. 17-23, maio/ago. 2008 .

MARIANO, Silvana Aparecida. O sujeito do feminismo e o pós-estruturalismo. Estudos Feministas, Florianópolis, v. 13, n. 3, p. 483- 505, setembro-dezembro/2005.

MARIVOET, Salomé. Assimetrias e afinidades de género no desporto. Disponível em: http:// www.aps.pt/cms/docs_prv/docs/DPR49f83c627ef5f_1.pdf. Acesso em: 28 nov. 2015.

MORENO, Rachel. A beleza impossível. São Paulo: Ágora, 2008.

MUSEU DO FUTEBOL. Visibilidade para o futebol feminino. Disponível em: https://www.google.com/culturalinstitute/exhibit/visibilidade-para-o-futebol-feminino/ gQuX4AQf?position=120\%2C0. Acesso em: 26 jan. 2016. 
PISCITELLI, Adriana. Re-criando a categoria mulher? Disponível em: http://www. culturaegenero.com.br/download/praticafeminina.pdf. Acesso em: 20 maio 2018.

PRADO, José Luiz Aidar. O leitor infiel diante dos mapas da mídia semanal performativa. Revista Fronteiras. v. 7, n. 1, p. 39-46, janeiro/abril 2005.

PORTAL IMPRENSA. Preparação e tempo de estrada são essenciais para se tornar comentarista esportivo. Disponível em: http://www.portalimprensa.com.br/especialcarreira/ mercado_05.asp. Acesso em: 20 ago 2017.

RAMOS, Regina Helena de Paiva. Mulheres jornalistas: a grande invasão. São Paulo: Imprensa Oficial do Estado de São Paulo: Faculdade Cásper Líbero, 2010.

RIBEIRO, José Hamilton. Jornalistas: 1937 a 1997. São Paulo: Imprensa Oficial do Estado, 1998.

SCOTT, Joan. O enigma da igualdade. Estudos Feministas, Florianópolis, v. 13, n. 1, p. 11-30, janeiro-abril 2005.

SIQUEIRA, Shymenne Costa. Jornalismo esportivo: a inserção da mulher jornalista no núcleo esportivo das emissoras de TV de Belo Horizonte. Monografia. Centro Universitário de Belo Horizonte Uni-BH, Belo Horizonte, 2005. Disponível em: http://www.convergencia.jor.br/ bancomonos/2005/Shymenne.pdf. Acesso em: 28 out 2015.

SOUSA, Jorge Pedro. Elementos de teoria e pesquisa da comunicação e dos media. Porto: Edições Universidade Fernando Pessoa, 2006.

TAVARES, Mariza. Manuel de redação CBN. São Paulo: Globo, 2011.

TAVARES, Núbia. Ana Zimmermann: pioneira no futebol da Globo. Disponível em: http:// www.papodebola.com.br/papoespecial/20050727.htm. Acesso em: 16 out 2015.

THEBERGE, N. Gender and sport. In J. Coakley \& E. Dunning (Eds.). Handbook of sports studies. London: Sage Publications, 2000, pp. 61-76. 
${ }^{1}$ Possui graduação em Comunicação Social - Relações Públicas pela Universidade Estadual Paulista Júlio de Mesquita Filho (2006), mestrado em Comunicação pela Universidade Estadual Paulista Júlio de Mesquita Filho (2010) e doutorado em Comunicação pela Universidade Estadual Paulista, UNESP (2018). Atualmente é professora da Associação de Escolas Reunidas LTDA, da Anhanguera e do Centro Universitário Adventista de São Paulo (UNASP). E-mail: tutoraead. noemibueno@gmail.com

2 Docente do Programa de Pós-graduação em Comunicação e do Departamento de Ciências Humanas da Faculdade de Arquitetura, Artes e Comunicação da Universidade Estadual Paulista (Unesp/Bauru). É Doutor em Ciências da Comunicação pela Escola de Comunicações e Artes da Universidade de São Paulo e Mestre em Comunicação e Semiótica pela Pontifícia Universidade Católica de São Paulo. É líder do GECEF (Grupo de Estudos em Comunicação sobre Esporte e Futebol) e integrante do LUDENS (Núcleo Interdisciplinar de Estudos sobre Futebol e Modalidades Lúdicas).E-mail: jose.marques@unesp.br 